\title{
NEURO-BEHÇET
}

\section{Report of three clinically distinct cases}

\author{
Giorgio Fabiani', Sérgio Monteiro de Almeida², Francisco M.B. Germiniani ${ }^{3}$, \\ Hélio Afonso Ghizoni Teive², Edison Matos Nóvak², Rosana Hermínia Scola², \\ Alessandra Zanatta ${ }^{3}$, Patrícia Coral ${ }^{3}$, Lineu Cesar Werneck ${ }^{4}$
}

\begin{abstract}
We report three patients who collectively have very representative clinical forms of neuro-Behçet and different neurological findings. The first case, male, 49 years old, presents symptoms similar to multiple sclerosis. The second case, male 15 years old, presents with parenchymatous compromise and an association with antiphospholipid antibody. And the third case, female 25 years old, presents an acute meningitis. NeuroBehçet must always be included as a differential diagnosis of neurological disorders that have any difficulties in establishing a definite diagnosis.
\end{abstract}

KEY WORDS: neuro-Behçet, Behçet's disease, cerebrospinal fluid.

Neuro-Behçet: relato de três casos clinicamente distintos

RESUMO - Relatamos três pacientes com formas bem representativas de neuro-Behçet e com diferentes apresentações clínicas e manifestações neurológicas. 0 primeiro caso é o de um homem, 49 anos e que apresenta manifestações clínicas similares à esclerose múltipla. 0 segundo caso é o de um adolescente de 15 anos, com comprometimento parenquimatoso e doença de Behçet associada à presença de anticorpo antifosfolipide. E o terceiro é caso de uma mulher de 25 anos apresentando quadro de meningite. NeuroBehçet deve ser sempre incluída em casos de desordens neurológicas que apresentem dificuldades para o estabelecimento de um diagnóstico definitivo.

PALAVRAS-CHAVE: neuro-Behçet, doença de Behçet, liquor.

Since Behçet's first description in 1937 of the triad of aphthous stomatitis, genital ulcers, and recurrent uveitis (seen in a ten-year period) ${ }^{1}$, the interest in this disease has just been increasing. Behçet's disease $(B D)$ is a multisystem vasculitis with recurrent symptoms and may show a myriad of clinical features ${ }^{2-4}$, with microscopic findings of great vessels arteritis ${ }^{5,6}$. The pathology of lesions consists of widespread vasculitis. Eyes, skin, joints, oral cavity, blood vessels and central nervous system (CNS) are usually involved ${ }^{6,7}$. BD's aetiology remains unknown, even though there are several hypothesis about its origin $^{6,7}$, with some pointing towards genetical factors. It presumably affects more people in Japan and in the Mediterranean region and less people in Central Europe and North America ${ }^{6,7}$. Its variable prevalence can be related to the presence or lack of the HLA-B51 e B52 antigen in some ethnical groups ${ }^{6-10}$.
It affects one in every 10000 to 30000 persons, but its prevalence can be as high as 80-370/ 100000, as seen in Turkey. In most studies BD is twice more common in males than in females ${ }^{7}$, but in Japan and Chorea it is more common in women. The triggering factor of the disease can be the exposition to streptococcal antigens ${ }^{11}$, viral antigens ${ }^{5,6}$ or environmental factors such as exposure to heavy metals, organophosphorate compounds ${ }^{6}$ and certain foods. Its epidemiological distribution and forms of clinical presentation also vary according to geographical distribution ${ }^{8}$. Its main clinical features are recurrent oral and genital ulcers, ocular inflammation (uveitis) and skin lesions such as erythema nodosum and acne-like lesions $\mathbf{s}^{1,3,4,6,12}$. In the majority of patients the first clinical symptom is the appearance of recurrent ulcers affecting patients who are 20 to 35 years-old ${ }^{6,12-14}$. Neurological compromise can

Study performed at the Service of Neurology of the Hospital de Clínicas da Universidade Federal do Paraná (UFPR): ${ }^{1}$ Neurologist/ Mastership student in Internal Medicine; ${ }^{2}$ Assistant Professor of Neurology, ${ }^{3}$ Resident in Neurology; ${ }^{4} \mathrm{Head}$ of the Service of Neurology.

Received 3 July 2000, received in final form 20 October 2000. Accepted 31 October 2000.

Dr. Giorgio Fabiani - Rua Paula Gomes 734/202 - 80510-070 Curitiba PR - Brasil. Fax: 5541264 3606. E-mail: giorgiof@osite.com.br 
range from 4 up to $49 \%$ of all patients $3,4,6,12-14$. Diagnosis of BD is based on the International Study Group for Behçet's Disease diagnostic criteriaa ${ }^{15,16}$ (Table 5).

All the patients we report underwent an extensive laboratory investigation, and both blood and cerebrospinal fluid (CSF), included IgG/lgA/lgM and albumin, protein electrophoresis, VDRL, ANCA and FAN, had no abnormal results.

\section{CASES}

Case 1. White, male, 49 years old. The patient presented 7 years before admission with oral ulcers, painful vesiculous lesions on lips, oral cavity mucous membrane and penis glans. The lesion in genitalia consisted of a craggy ulcer $10 \mathrm{~mm}$ by $0.75 \mathrm{~mm}$ (glans) and similarly there were three craggy ulcers on buccal mucosa. Also it was observed some scarring from previous ulcers. At the same time the patient began to present a progressive weakness of the left lower limb (LLL), which worsened for 6 months since it reached a plateau for 7 years. His clinical picture remained stable during this seven-year period with continuous use of azathioprine $150 \mathrm{mg}$ daily. Latter, the patient developed new oral and genital ulcers simultaneously to a worsening of the muscular power on the right leg initially. After some months the patient became paraparetic. Neurological examination disclosed an increased muscle tone (spastic) on the lower limbs, a grade III muscle strength on the left lower limb and grade I on the right lower limb, bilaterally increased aquillean and knee jerks and extensor plantar responses. He developed a severe leukopenia, probably due to azathioprine. The patient has never presented ocular symptoms. It was performed a biopsy of the oral and genital ulcers. They only revealed signs of non specific chronic and acute inflammation (pathological study did not reveal herpesinfected epithelial cells). Treatment with thalidomide 200 mg daily was instituted with remission of the ulcers. Nevertheless, the neurological symptoms have progressed. A high protein level in the CSF (Table 1), despite a normal number of cells, was detected in serial examinations. We have not found any evidence of oligoclonal banding of immunoglobulins in CSF. MRI study of the brain has disclosed several periventricular lesions with enhancing signal on T2 weighted images and low signal on T1 weighted images. The clinical picture has worsened, which suggested a chronic-progressive course.

Case 2. White, male, 15 years-old. When the patient was one year old he started having bouts of intermittent night fever from unknown origin. One year later he developed a gait ataxia with several falls for 30 days, resolved spontaneously. When he was five years old he presented an acute dystonic posture after haloperidol use, followed by right hemiparesis. Four years later a pro- gressive right hemidystonia developed and painful recurrent oral ulcers appeared. The patient had not had neither genital ulcers or ocular symptoms. Since the need of a long lasting treatment and presence of severe oral ulcers, we decided for a treatment with thalidomide 100 $\mathrm{mg} /$ day. This treatment has led our patient to a complete remission of the oral lesions and stabilization of neurological symptoms. He has been stable since then (now for almost 6 years). Physical examinations were normal, except for 2 craggy ulcers $0.5 \mathrm{~cm}$ diameter on oral mucosa. A neurological examination disclosed spastic right hemiparesis, disarthria, right body dystonia, gait ataxia and increased tendon reflexes on the left side. A biopsied oral ulcer revealed signs of chronic and acute inflammation around the ulcer; the study has not shown herpes-infected epithelial cells. MRI study of the brain disclosed an area of pallidal necrosis and lacunar lesion on the left and a right ischaemic pallidal lesion. The patient has had a positive antiphospholipid antibody ( $\lg \mathrm{G}=28 \mathrm{U} / \mathrm{l}$ and $\lg \mathrm{M}=30 \mathrm{U} / \mathrm{l})$. CT scan of the brain revealed low intensity sign on the right globus pallidus, probably due to ischaemic process. The CSF was completely normal (Table 1) and there was no evidence of oligoclonal banding of immunoglobulins in CSF.

Case 3. White, female, 25 years-old. The patient was admitted with symptoms and signs of sepsis, consciousness compromise, visual disturbances, meningism and intense enterorrhagia. The patient also had painful ulcerated lesions in both oropharynx and vagina, as well as skin lesions. She had a history of recurrent oral ulcers, which lasted for several weeks, at least four times a year. By physical examination we detected pustulous lesion on both face and torso, diagnosed as pyodermitis, several small craggy ulcers in the oropharynx mucosa and erythema nodosum in the lower limbs. Also in the genitalia we found some ulcers on the labium major. Eye fundus examination disclosed bilateral hemorrhagic retinal exudates and papilledema. Stiff neck, Brudzinski sign and right hemiparesis were also present. An elevated erythrocyte sedimentation rate $(110 \mathrm{~mm}$ in the first hour), 34000 leukocytes and 52\% rods were found in leukocyte count. Brain CT scan was normal. Fluorescein angiogram revealed papilledema with leakage of dye from disk and inflam-

Table 1. Main CSF findings in the three studied patients.

\begin{tabular}{lccc}
\hline & Case 1 & Case 2 & Case3 \\
\hline Cells/mm3 & 0,3 & 0,6 & 510 \\
Rods(\%) & - & - & 70 \\
Lymphocytes (\%) & - & - & 30 \\
Glucose (mg/dl) & 68 & 69 & 58 \\
Protein (mg/dl) & 98 & 30 & 101 \\
Gammaglobulin (\%) & 12,3 & 7,2 & - \\
\hline
\end{tabular}


matory exudates. The patient was treated with pulse of methylprednisolone $1 \mathrm{~g}$ per day during 5 days. She has shown a complete recovery since was initiated a corticosteroids treatment, with normalization of first CSF findings (Table 1). From then, she has been using azathioprine $150 \mathrm{mg} /$ day and is still in remission of $B D$.

\section{DISCUSSION}

$\mathrm{BD}$ is a systemic disease, frequently compromising the skin and mucous membranes, joints, kidneys, lungs, gastrointestinal organs and nervous system. Recurrent oral ulcers can be found in $99 \%$ of all patients and they are the first symptom in as much as $70 \%$. Ocular compromise can be found in up to $90 \%$ of the patients and can cause blindness, skin lesions in $85 \%$ of cases and genital ulcers in approximately $70 \% \%^{1,3,4,6,6,8,16-23}$.

$\mathrm{BD}$ diagnosis is based on clinical criteria (Table $5)^{15,16}$. Oral ulcers and two other major criteria are necessary for the diagnosis ${ }^{15,16,24,25}$; lack of oral lesions can be used to exclude up to $3 \%$ of patients who have a BD compatible clinical picture but without oral or genital ulcers ${ }^{24,25}$. The diagnostic criteria cannot be completely met on a first evaluation

Table 2. Main clinical findings (\%) of Behçet's disease, according to different authors.

\begin{tabular}{lccc}
\hline Clinical picture & $\begin{array}{c}\text { Bosi \& } \\
\text { col. }^{24} \\
(\mathrm{n}=32)\end{array}$ & $\begin{array}{c}\text { Akman-Demir } \\
\& \text { col. }{ }^{2} \\
(\mathrm{n}=200)\end{array}$ & $\begin{array}{c}\text { Chajek \& } \\
\text { col. }^{17} \\
(\mathrm{n}=41)\end{array}$ \\
\hline Oral ulcers & 100 & 100 & 98 \\
Ocular lesions & 59 & 66 & 76 \\
Genital ulcers & 59 & 94 & 88 \\
Skin lesions & 94 & 84 & 88 \\
Pathergy test & 3 & 83 & 73,2 \\
Retinal vasculitis / & 22 & 66 & 29,3 \\
Ocular compromise & & & - \\
Joint compromise & 88 & 56 & 31,7 \\
Erythema nodosum & 66 & - & 29,3 \\
Cardiac manifestations & 3 & 3,5 & - \\
CNS symptoms & 16 & 100 & - \\
Gastrointestinal lesions & 22 & 3 & - \\
Renal compromise & 3 & - & - \\
Dermographism & - & - & - \\
Lung compromise & - & 7 & - \\
Family history & 12 & - & - \\
\hline & & & - \\
\hline
\end{tabular}

in up to $75 \%$ of cases, specially in children ${ }^{25,26}$. The terms "complete" and "incomplete" BD are based on the number of major diagnostic criteria found: oral ulcers, genital ulcers, ocular compromise and skin findings.

When all four major criteria are found, it can be said that the patient has complete $\mathrm{BD}$, and when only 2 or 3 major criteria are found, the patient has the called incomplete BD. Thus, our two male cases can be classified as incomplete forms of $\mathrm{BD}$, whereas the female patient was classified as complete BD, because all 4 major criteria were present. The main clinical findings of BD are summarized in Table 2 .

Neurological compromise can range from 4 up to $49 \%$ of all patients $3,4,6,12-14,17,18$. Parenchymatous compromise is the most common form of neurological compromise ${ }^{6}$, with its main clinical features found in Table 3. It is important to highlight that neurological compromise leads to a bad prognosis ${ }^{6}$. Neurological compromise can vary greatly, sometimes leading to a misdiagnosis of multiple sclerosis with evidence of multifocal CNS compromise ${ }^{27}$. CNS compromise frequently starts with headache, fever and aseptic meningitis. Pyramidal signs, pseudobulbar paralysis, cerebellar signs, cranial nerve palsies are the most common neurological signs and can usually be found in patients with symptoms of meningitis ${ }^{5,6}$. Brainstem signs, seizures, aphasia, extrapyramidal signs, dementia and myelopaty can also be found ${ }^{6,7}$. Papilledema, subarachnoid hemorrhage, benign intracranial hypertension and tremor are uncommon ${ }^{7}$. The clinical course can be that one of a single acute attack, a silent neurological compromise, an attack-remission course or a primarily progressive course, with predisposition to recurrence when immunosuppressive drugs are withdrawn $3,5,6$.

The periventricular lesions found in the MRI study of Patient 1 suggest a demyelinating process, similar to one found in multiple sclerosis, even though recurrent oral or genital ulcers are diagnostic for BD. After reviewing the literature, only a few case reports have demyelinating lesions similar to those of multiple sclerosis ${ }^{27}$.

Case 2 presented a stroke of basal ganglia associated to high titters of antiphospholipid antibody. It is important to remember that stroke-like lesions are one of the most common manifestations of BD in the CNS. Antiphospholipid antibody can be found in a varying rate of 0 to $50 \%$ of all cases and can be like thrombotic syndromes or vascular occlusions in 
Table 3. Neurological findings (\%) in Behçet disease patients, according to different authors.

\begin{tabular}{lcc}
\hline Signs and symptoms & Akman-Demir \& col. ${ }^{6}$ & Serdaroglu \& col. ${ }^{14}$ \\
\hline Pyramidal signs & $96 ;$ in $2 / 3=$ bilateral & 82 \\
Hemiparesis & $60 ;$ in $90 \%=$ unilateral & - \\
Behavioral findings & $54 ; 1 / 3$ apathy, $2 / 3$ lack of social inhibition & - \\
Impotence / sphincter compromise & 48 & - \\
Non internuclear ophthalmoplegia & 15,4 & 12 \\
Internuclear ophthalmoplegia & 1,9 & - \\
Bulbar / pseudobulbar signs & 3,8 & 24 with cerebellar signs \\
Bulbar signs and ophthalmoplegia & 6,2 & 24 \\
Pyramidal-cerebellar syndrome & 33 & - \\
Sensitive compromise & 29 & Tremor and myoclonic jerks in $6 \%$ of the cases \\
Paraparesis & 11 & -
\end{tabular}

Table 4. Prognostic factors in Behçet disease patients with more than three years of disease, according to Akman-Demir \& co/6 .

Good prognosis

Normal CSF

Secondary or non-parenchymatous compromise

$<$ than 2 attacks

Non dependable at admission

Bad prognosis

\author{
Abnormal CSF \\ Parenchymatous compromise \\ $>$ than 2 attacks \\ Dependable at admission \\ Recurrence during corticosteroids withdrawal \\ Progressive course, either primary or secondary
}

patients with BD. It is also related to a worse prognosis ${ }^{5-7,28-31}$. CSF abnormalities are definitely linked to a worse prognosis ${ }^{2,6}$, such as chronically increased protein, as seen in Case 1 . Table 4 presents the prognostic factors of $\mathrm{BD}^{6}$. Other CSF findings of $B D$ are lost of integrity of the BBB (found in up to $42 \%$ ) intrathecal synthesis of immunoglobulins as seen by qualitative and quantitative ${ }^{28}$ and oligoclonal bands can be found in $8 \%$ of all ${ }^{31}$.

Case 3 was the only one whose neurological symptoms presented meningoencephalitis, as well as oral and genital ulcers, ocular compromise and severe enterocolitis. The most common CSF abnormalities are moderate pleocytosis in $27 \%$ of cases, with pre-
Table 5. Behçet's disease diagnostic criteria*.

Major criteria

1. Recurrent oral and genital ulcerations

2. Eye lesions

3. Skin lesions (erythema nodosum-like or folliculitis)

4. Positive pathergy test (non infected pustules in the site of trauma)

Minor criteria
1. Arthritis or arthralgia
2. Deep venous thrombosis
3. Subcutaneous thrombophlebitis
4. Epididimitis
5. Family history
6. Gastrointestinal lesions
7. CNS symptoms
8. Vascular lesions

*International Study Group for Behçet's disease (1990) ${ }^{15,16}$.

dominant lymphocytes, and increased protein content in $19 \%$, with both occurring in $37 \%$ of cases. Total number of cells rarely exceeds 200 cells $/ \mathrm{mm} 3$, but occasionally it can be higher than 500 cells $/ \mathrm{mm} 3$ with rods and lymphocytes ${ }^{32}$. Recurrent meningitis is common ${ }^{28}$. Case 1 had an increased protein throughout 7 consecutive years. After that period the patient had a progressive worsening in neurological symptoms, as well as increasingly greater lesions on MRI. Case 2 had a completely normal CSF study. Case 3 's clinical manifestation was an acute meningo- 
encephalitis, thus the CSF findings were clinically significant. In the first two cases, lumbar puncture was performed after the treatment had already been started, which can maybe explain the normal cell count.

We report a group of patients who collectively have the most common clinical forms of BD, including vasculitis form with antiphospholipid antibody (APLAB) and parenchymatous compromise. Two patients presented less common symptoms, similar to multiple sclerosis in one and to meningitis in the other. Only in the second case an APLAB was found in the blood and was probably involved with bilateral infarct of the basal ganglia.

In conclusion, NB must always be included as a differential diagnosis of neurological disorders that have any difficulty in a definite diagnosis.

\section{REFERENCES}

1. Behçet H. Uber rezidivierende Aphtöse, durch ein Virus verursachte geschwure am Mund, am Auge und an den Genitalien. Derm Woschenscr 1937;105:1152-1157.

2. Akman- Demir G, Bayaka-Kurt B, Serdaroglu P, et al. Seven year followup of neurologic involvement in Behçet syndrome. Arch Neurol 1996;53:691-694.

3. O'Duffy JD, Goldestein NP. Neurologic involvement in seven patients with Behçet's disease. Am J Med 1976;61:170-178.

4. O'Duffy JD, Carney A, Deodhar S. Behçet's disease; report of 10 cases, 3 with new manifestations. Ann Intern Med 1971;75:561-570.

5. O'Duffy JD. Vasculitis in Behçet's disease. Rheum Dis Clin N Am 1990;16:423-431

6. Akman- Demir G, Serdaroglu P, Tasçi B, and the Neuro-Behçet Study Group. Clinical patterns of neurological involvement in Behçet's disease:evaluation of 200 patients. Brain 1999;122:2171-2182.

7. Kaklamani VG, Vaiopoulos G, Kaklamanis PG. Behçet's disease. Semin Arthr Rheum 1998;27:197-217.

8. Geraint JD. Behçet's disease. BJCP 1990;44:364-368.

9. Arber N, Klein T, Meiner Z, Pras E, Weinberger A. Close association of HLA-B51 and B52 in Israeli patients with Behçet's syndrome. Ann Rheum Dis 1991;50:351-353.

10. Yazici H, Basaran G, Hamuryudan V, et al. Ten year mortality in Behçet's syndrome. Br J Rheumatol 1996;35:139-142.

11. Powell RJ, Dunstan S. Immunopathology of Behçet's disease. Postgrad Med J 1991;67:503-505.
12. Zouboulis C. Epidemiology of Adamantiades-Behçet's disease. Ann Med Int 1999;150:488-498.

13. Wechsler B, Dell Isola B, Vidailhet M, et al. MRI in 31 patients with Behçet's disease and neurological involvement: prospective study with clinical correlation. J Neurol Neurosurg Psychiatry 1993;56:793-798.

14. Serdaroglu P, Yazici H, Ozdemir C, Yurdakul S, Bahar S, Atkin E. Neurologic involvement in Behçet's syndrome: a prospective study. Arch Neurol 1989;46:265-269.

15. International Study Group for Behçet's Disease. Criteria for diagnosis of Behçet's disease. Lancet 1990;335:1078-1080.

16. International Study Group for Behçet's Disease. Evaluation of diagnostic (classification) criteria in Behçet's disease: towards internationally agreed criteria. Br J Rheumatol 1992;31:299-308.

17. Chajek T, Fainary M. Behçet's disease: report of 41 cases and a review of the literature. Medicine 1975;54:179-196.

18. Bousser MG. Les manifestations neurologiques de la maladie de Behçet. Revue Med 1974;35:2317-2383.

19. Wong RC, Ellis CN, Diaz LA. Behçet's disease. Int J Dermatol 1984;23:2532.

20. Debray CH, Paolaggi JA, Couturier D, Crespon B. Manifestations digestives de la maladie de Behçet. Revue Med 1974;36:2367-2370.

21. Touraine R. Syndrome de Behçet:manifestations cutaneo-muqueses. Revue Med 1974;35:2299-2302.

22. Touraine R. Le syndrome de Behçet: historique et nosologie. Revue Med 1974;35:2293-2296.

23. O'Duffy JC. Critères proposés pour la maladie de Behçet et notes thérapeutiques. Revue Med 1974;36:2371-2379.

24. Bosi Ferraz M, Walter SP, Hermann R, Atra E. Sensitivity and specificity of different diagnostic criteria for Behçet's disease according to the latent class approach. Br J Rheum 1995;34:932-935.

25. Koné PI, Chabrol B, Riss JM, Maneini J, Raybaud C, Garnier JM. Neurologic onset of Behçet's disease: a diagnostic enigma in childhood. J Child Neurol 1997;12:237-241.

26. Tohme A, Haddad F, Ghayad E. Neurologic manifestations in Behçet's disease: 16 cases in a cohort of 110 patients. Ann Med Interne 1997; 148:118-124.

27. Yamamori $C$, Ishino $H$, Inagaki $T$, et al. Neuro Behçet disease with demyelination and gliosis of the frontal white matter. Clin Neuropathol 1994;13:208-215.

28. Hinchey JA, Sila CA. Cerebrovascular complications of rheumatic disease. Rheum Dis Clin N Am 1997;23:293-317.

29. Fessler BJ. Thrombotic syndromes and autoimmune diseases. Rheum Dis Clin N Am 1997;23:461-479.

30. Boggild MD, Sedhev RV, Fraser D, Heron JR. Cerebral venous sinus thrombosis and antiphospholipid antibodies. Postgrad Med J 1995;71:487-489.

31. McLean BN, Miller D, Thompson EJ. Oligoclonal banding of IgG in CSF, blood-brain barrier function and MRI findings in patients with sarcoidosis, systemic lupus, erythematosus and Behçet's disease involving the nervous system. J Neurol Neurosurg Psychiatry 1995;58:548-554.

32. Fishman RA. Cerebrospinal fluid in diseases of the nervous system. 2. Ed. Philadelphia: Saunders, 1992. 